\title{
Social inclusion and immunisation
}

\author{
Kerina Tull \\ University of Leeds Nuffield Centre for International Health and Development \\ 3 February 2021
}

\section{Questions}

- What are the social and cultural challenges related to the equitable roll-out, distribution and access of COVID-19 vaccines, tests and treatments?

- How does this impact upon excluded and marginalised groups (e.g. women and girls, people with disabilities, LGBTI communities)?

- What have we learned from previous pandemics and vaccine roll-out on this issue?'

\section{Contents}

1. Summary

2. Equitable COVID-19 vaccine roll-out, distribution, and access

3. Social and cultural challenges related to COVID-19 vaccine roll-out, distribution, and access

4. Impacts of these challenges on excluded and marginalised groups

5. Lessons learned from previous pandemics and vaccine roll-out

6. References

The K4D helpdesk service provides brief summaries of current research, evidence, and lessons learned. Helpdesk reports are not rigorous or systematic reviews; they are intended to provide an introduction to the most important evidence related to a research question. They draw on a rapid deskbased review of published literature and consultation with subject specialists. 


\section{Summary}

Social inclusion is an important determinant of health. The current COVID-19 epidemic is both a health and societal issue (Rajan et al., 2020). Therefore, group historically excluded and marginalised in terms of healthcare will suffer if COVID-19 vaccines, tests, and treatments are to be delivered equitably.

This rapid review is exploring the social and cultural challenges related to the roll-out, distribution, and access of COVID-19 vaccines, tests, and treatments. It highlights how these challenges impact certain marginalised groups. Case studies are taken from sub-Saharan Africa (the Democratic Republic of Congo, South Africa), with some focus on South East Asia (Indonesia, India) as they have different at-risk groups. Lessons on this issue can be learned from previous pandemics and vaccine roll-out in low- and mid-income countries (LMICs).

Key points to highlight:

- Successful COVID-19 vaccine roll-out will only be achieved by ensuring effective community engagement, building local vaccine acceptability and confidence, and overcoming cultural, socio-economic, and political barriers that lead to mistrust and hinder uptake of vaccines (Burgess et al., 2020).

- Main challenges of social/cultural issues related to equitable roll-out of COVID-19 vaccines, tests, treatments include lack of acceptance, and discrimination.

- "Hard-to-reach" groups focus on vaccine delivery (high levels of demand, but face low supply), whereas "hard-to-vaccinate" groups centres on vaccine uptake and acceptance (low levels of demand despite high supply) (Ozawa et al., 2019). Both groups are impacted by social challenges, resulting in adverse health outcomes (including those with co-morbidities) and socio-economic inequalities, e.g. due to lockdowns.

- However, the difference between "hard-to-reach" and "hard-to-vaccinate" populations is unclear based on current literature (Ozawa, 2019). For example, people living with disabilities (PLWD) can be hard-to-reach (e.g. due to poverty, their living circumstances, or lack of mobility) and hard-to-vaccinate (e.g. due to mistrust of health systems). A more accurate term for these groups would be "hardly reached" (Dodds \& Fakoya, 2020).

- COVID-19 has had a disproportionate impact on racial and ethnic groups in high income countries such as the UK and USA. However, there is a lack of similar data from LMICs. UN data shows that COVID-19 has a disproportionate impact on LGBTQI persons $(\mathrm{OHCHR}, 2020 \mathrm{c})$. However, the literature on this is also limited. Older people have also been excluded for socio-economic reasons, e.g. during lockdowns.

- Certain minority groups may be more at risk of being left behind in COVID-19 vaccination programmes, as hard-to-reach groups were at a greater risk of exposure and transmission of Ebola, for example the BaTwa indigenous group due to gender norms and discrimination on basis of ethnic group (Lenhardt, 2020). This also made them hardto-vaccinate.

- Main demand side factors that influenced vaccine uptake was religious beliefs and lack of trust/ misinformation about COVID-19 (de Figueiredo et al., 2020).

- Rafaeli \& Hutchinson (2020) found that girls' education, social protection, unintended pregnancies, access to health services, poverty, livelihood, land rights, women's and 
girls' informal employment, food security and nutrition, female health workforce, and access to WASH in sub-Saharan Africa were all affected by COVID-19.

- Assessments of vaccination coverage for the general population may not be sufficient (Weiss et al., 2009: 362). Spatial heterogeneity (i.e. uneven distribution within an area) has been used to determine the success of immunisation programmes, as well as risk of disease persistence (Brownwright et al., 2017). Gap analysis, such as that by EBODAC, can identify vaccine roll-out supply and demand needs and adherence.

- Lessons learned: There has been disagreement in the Médecins Sans Frontières (MSF) and World Health Organization (WHO) vaccine distribution, e.g. Ebola responses. The roll-out of the H1N1 or swine flu vaccine in 2009 was plagued by shortages and miscommunication, which led to a drop in public confidence. A lot of lessons learned about roll-out involve communication - including that the government should underpromise what it can do and then over-deliver. Any campaign must aim to create trust, and involve local communities in planning processes (IRC, 2021). One important lesson from Ebola is that understanding social dynamics is essential to designing robust interventions, and should be a priority in public health and emergency planning (Wilkinson et al., 2017).

This review draws mostly on grey and academic literature, including COVID-19 perspectives. However, there are potential factors in social inclusion that may never have been fully studied in relation to mass immunisation campaigns and, therefore, do not appear in any literature (published or unpublished) (Weiss et al., 2009: 364). In terms of terminology, immunisation (a process by which a person becomes protected against a disease through vaccination) is often used interchangeably with vaccination (the act of introducing a vaccine into the body to produce immunity to a specific disease). In terms of availability of data, the majority of data related to inclusion in previous pandemics from LMICs is available for Ebola.

\section{Equitable COVID-19 vaccine roll-out, distribution, and access}

According to international human rights standards, all people have an equal right to the highest attainable standard of physical and mental health, which includes access to health care, as well as to the underlying determinants of good health (Willen et al., 2017). The United Nations (UN) states that "it is imperative that access to COVID-19 vaccines and treatment is provided to all without discrimination and prioritized for those who are most exposed and vulnerable to the risk of COVID-19" (OHCHR, 2020a). However, discussions continue about the ethical challenges of ensuring fair access to COVID-19 vaccines within and across countries, and which groups should be prioritised (Burgess et al., 2020).

People in vulnerable situations who are often neglected from health services, goods and facilities, include: women; indigenous peoples; people living with disabilities (PLWD); older persons; minority communities; internally displaced people (IDP); persons in overcrowded settings and in residential institutions; people in detention; homeless persons; migrants and refugees; people who use drugs, as well as lesbian, gay, bisexual, transgender, queer/questioning, and intersex (LGBTQI) persons (OHCHR, 2020a). Many of them may have experienced poverty, and find themselves in situations where they are most likely to be 
exposed to the risk of contagion; yet are the least likely to be protected from COVID-19, or supported by adequate and timely tests and health services (OHCHR, 2020b).

To ensure the equitable distribution of COVID-19 vaccine doses to help protect the most-at-risk groups - i.e. those with greater chances of being infected with COVID-19 or of getting very sick in all participating countries, Gavi- the Vaccine Alliance and the World Health Organization (WHO) have developed a framework through the COVID-19 Vaccines Global Access (COVAX) Facility. COVAX is the vaccines pillar of the Access to COVID-19 Tools (ACT) Accelerator. Several low- and middle-income countries (LMICs) will get their vaccines through COVAX, including many African countries that would not otherwise be covered. ${ }^{1}$ COVAX will offer vaccine doses for at least $20 \%$ of these countries' populations. ${ }^{2}$ However, the reality may be much lower, so all vulnerable groups may not be reached (IRC, 2021). Few south east Asian countries (Mongolia, Myanmar, Nepal) are seeking assistance from the Gavi and COVAX programmes to acquire vaccines (ASEAN Briefing, 2021):

\section{Case study: Indonesia}

Indonesia is due to start a mass inoculation campaign with Chinese vaccine Sinovac in February 2021, and will also be seeking assistance from the COVAX programme. ${ }^{3}$ According to the Health Ministry's Disease Control and Prevention, instead of vaccinating older people in the first phase, after frontline workers and support staff, vaccinations will only be provided to citizens aged 1859 years. This is because they make up the public work force, which needs to be protected first to boost the economy. ${ }^{4}$ However, it puts older people at risk of becoming marginalised.

It is uncertain how the country can source enough vaccines to reach a sizeable part of its population (ASEAN Briefing, 2021). It is also unknown how other high-risk groups will be targeted, e.g. how those with psycho-social disabilities will be vaccinated (especially as almost all of them do not have computers, media or phones to access COVID-19 information in their psychiatric facilities). ${ }^{5}$

Indonesia is culturally diverse with more than 1,300 ethnic groups and six official religions. ${ }^{6}$ Over $40 \%$ of the population are Javanese. ${ }^{7}$ However, many ethnic groups have only hundreds of members, and are indigenous only to certain regions of Indonesia. Therefore, the range of health challenges is daunting, spread across almost 18,000 islands and 730 languages. ${ }^{8}$ Religious

\footnotetext{
${ }^{1}$ COVAX Commitment agreements (as of 15 December 2020):

https://www.gavi.org/sites/default/files/covid/pr/COVAX_CA_COIP_List_COVAX_PR_15-12.pdf

2 WHO (2020). COVAX: Working for global equitable access to COVID-19 vaccines:

https://www.who.int/initiatives/act-accelerator/covax

${ }^{3}$ Indonesia aims for halal ruling before COVID vaccine roll out. 7 January 2021:

https://www.aljazeera.com/news/2021/1/7/indonesia-aims-for-halal-ruling-before-covid-vaccine-roll-out

4 Ekawati A (2021). Indonesia's COVID vaccination campaign prioritizes workers. 22 January 2021.

https://www.dw.com/en/indonesias-covid-vaccination-campaign-prioritizes-workers/a-56316852

${ }^{5}$ COVID-19 and The Forgotten People (Indonesia). 16 April 2020:

https://www.internationaldisabilityalliance.org/covid19-indonesia

${ }^{6}$ Widayanti AW, Green JA, Heydon S, Norris P (2020). Health-Seeking Behavior of People in Indonesia: A

Narrative Review. J Epidemiol Glob Health, 10(1):6-15. DOI: 10.2991/jegh.k.200102.001

7 World Population Review (2021). Indonesia Population 2021 (Live):

https://worldpopulationreview.com/countries/indonesia-population

8 Successes and challenges for health in Indonesia. 5 January 2019:

https://www.thelancet.com/journals/lancet/article/PIIS0140-6736(18)33258-6/fulltext
} 
acceptabilty is a major factor: as Indonesia is the world's most populous Muslim-majority country, with $87 \%$ reported Muslims, the vaccine has been required to pass halal certification prior to use (ASEAN Briefing, 2021).

\section{Case study: South Africa}

South Africa has so far secured 20 million vaccine doses. ${ }^{9}$ The first batch is expected to arrive at the beginning of February 2021, with vaccine distribution starting approximately two weeks later. South Africa expects to acquire doses for approximately $10 \%$ of the population through COVAX, and has been told it will receive them from April through to June 2021. However, there is no detailed timeline for a programme aiming to vaccinate as many as 40 million people (Mwai, 2021). The Progressive Health Forum of South Africa has criticised the government for their lack of planning into how these vaccines are going to be deployed. ${ }^{10}$ To help with this, the South African COVID-19 Vulnerability Index (VIndex) online mapping tool has been developed to identify populations that are at multiple risk, and to identify areas where the population are considered most vulnerable ${ }^{11}$ to COVID-19.

The country wants to vaccinate healthcare workers in the first wave, but with the number of workers estimated at 1.2 million, this first batch does not look like it will be enough. The roll-out distribution is further compounded by the fact that the vaccines are not currently authorised for use in children under the age of $16 .{ }^{12}$ The second wave would expand the roll-out to essential workers (e.g. fire fighters), individuals over 60 years, and people with comorbidities who are at particularly higher risk than most. In total, 16.5 million people are targeted in this phase. In the third phase, the general population older than 18 years would be the target - a total of 22.5 million people. ${ }^{13}$

\section{Social and cultural challenges related to COVID-19 vaccine roll-out, distribution, and access}

The COVID-19 crisis is not simply a health problem but a societal one: it impacts every single person in society one way or another (Rajan et al., 2020). The UN General Assembly calls for "the rapid scaling up of manufacturing and establishment of supply chains that promote and ensure fair, transparent, equitable, efficient and timely access to drugs and future COVID-19

\footnotetext{
9 South Africa has been seeking to source vaccines in three ways: via the WHO-backed COVAX Facility scheme, led by Gavi, the Vaccine Alliance, WHO and the Coalition for Epidemic Preparedness Innovations (CEPI); via arrangements made by the African Union, and through bilateral contracts with vaccine manufacturers.

10 Progressive Health Forum of SA slams government for delayed procurement of coronavirus vaccines. 4

January 2021: https://www.youtube.com/watch?v=uJViqu9hPDk

11 'Vulnerability' in this context refers to the demographic and socio-economic factors that affect the resilience of individuals and communities, and represent those more likely to be adversely affected when COVID-19 manifests itself (i.e. older people; those with underlying health conditions, and the population at risk such as exposed to increased health and social vulnerability - i.e. those who are poor or live in deprived conditions which impacts on health and sanitation; those who live in crowded areas or informal settlements which impacts on social distancing; and those who live in multi-generational households and large extended families in a single dwelling).

12 SABC News (2021). Government's COVID-19 immunisation plan unattainable Prof Madhi (4 January 2021): https://www.sabcnews.com/sabcnews/governments-covid-19-immunisation-plan-unattainable-prof-madhi/ ${ }^{13}$ Medical Brief (2021). Madhi: SA has no vaccination strategy, just an unrealistic goal (21 January 2021): https://www.medicalbrief.co.za/archives/madhi-sa-has-no-vaccination-strategy-just-an-unrealistic-goal/
} 
vaccines."14 Therefore, international co-operation remains a matter of necessity for and within all nations to ensure equitable distribution of therapies (Bollyky et al., 2020). However, research shows concerns about equity in access to COVID-19 vaccines, such as the interplay of ethnosocial-economic factors can hinder vaccine access (Chiriboga et al., 2020):

\section{Ethnic inequalities}

Ethnic inequalities in access to health services, representation and involvement in the COVID-19 response are critical to reaching communities at heightened risk of infection, and with limited access to treatment (Lenhardt, 2020). Health professionals often frame members of ethnic minority communities as "hard-to-reach" because of low engagement in population health screenings (Dodds \& Fakoya, 2020). However, it is more accurate to say these groups tend to be "hardly reached" by those who fail to understand the needs of marginalised people.

\section{Cultural and religious restrictions}

In some countries, minority ethnic or religious affiliation was associated with vaccination status during mass campaigns. For example, results of an evaluation of a mass polio campaign in India showed that unvaccinated children were more likely to be Muslims than Hindus, although Muslims represent a smaller proportion of the population than Hindus (Singh et al., 1997; Weiss et al., 2010: 361). Most religions have no prohibition against vaccinations; however, some have considerations, concerns or restrictions regarding vaccination in general, particular reasons for declining vaccination, or specific vaccine ingredients. ${ }^{15}$

\section{Lack of trust and vaccine acceptability}

Vaccine confidence refers to people not having trust in vaccines and/ or the health system that delivers them (Merriam \& Behrendt, 2020: 15). Prior to the COVID-19 pandemic, there has been a global decline in vaccine acceptability and uptake because of doubts about efficacy and safety, and the spread of misinformation about vaccines (Tull, 2019). A 2020 survey conducted by the Africa Centres for Disease Control and Prevention (Africa CDC), in partnership with the London School of Hygiene \& Tropical Medicine (LSHTM) has shown that a predominant majority $(79 \%$ average) of respondents in 15 African countries would take a COVID-19 vaccine if it were deemed safe and effective. ${ }^{16}$ However, before a vaccine is rolled-out, awareness and acceptance is crucial. For example, a report by the Infectious Diseases Research Collaboration (IDRC) in Uganda shows that religious leaders have claimed that "whites use drugs to cause infertility among [black] girls disguised as vaccines for immunisation" (Kamya, 2020: 25). Negative social influences by male spouses was another reason provided for not immunising children (Kamya, 2020: 22). Therefore, the importance of trusted messengers in encouraging behaviour change must be remembered (Merriam \& Behrendt, 2020: 56):

\footnotetext{
14 The United Nations General Assembly (2020). International cooperation to ensure global access to medicines, vaccines and medical equipment to face COVID-19.

15 Immunizations and Religion: https://www.vumc.org/health-wellness/news-resource-articles/immunizations-andreligion

${ }^{16}$ Majority of Africans would take a safe and effective COVID-19 vaccine - Africa CDC. 17 December 2020: https://africacdc.org/news-item/majority-of-africans-would-take-a-safe-and-effective-covid-19-vaccine/
} 


\section{Case study: Indonesia}

Indonesia witnessed a large drop in confidence between 2015 and 2019, partly triggered by Muslim leaders questioning the safety of the measles, mumps, and rubella (MMR) vaccine, and ultimately issuing a fatwa - a religious ruling - claiming that the vaccine was haram and contained ingredients derived from pigs and thus not acceptable for Muslims (de Figueiredo et al., 2020: 906).

\section{Cultural discrimination and stigma}

Globally, COVID-19 has also further marginalised historically oppressed and excluded groups, such as people living with disabilities (PLWD) (Johns et al., 2020). PLWD often live in isolation and are excluded from their communities, the education system, healthcare, and other vital services. Some are also hidden away by their families. ${ }^{17}$ Therefore, PLWD are more likely to experience worse discriminatory laws, as well as stigma (Armitage \& Nellums, 2020 in McKinney, 2020).

\section{Low access to COVID-19 vaccine tests}

WHO states that "Anyone with symptoms should be tested, wherever possible." However they add: "Where testing capacity is limited, tests should first be done for those at higher risk of infection, such as health workers, and those at higher risk of severe illness such as older people, especially those living in seniors' residences or long-term care facilities." ${ }^{18}$ However, a systematic review suggests that ethnic minorities and migrant groups have been less likely to implement public health measures, be tested, or seek care when experiencing symptoms due to barriers and inequities in the availability and accessibility of care (Sze et al. 2020):

\section{Case study: South Africa}

South Africa is still in an early phase of its COVID-19 epidemic, which means it will have to keep up screening, testing and tracing efforts for many months to come. The targeted testing in South Africa differs from the approach of most European governments that have relied on citizens coming forward for tests and then tracing their contacts (Cotterill , 2020). The level of testing in South Africa has now grown to more than 12,700 tests a day. The country has had more than 1.44 million cases and almost 44,000 deaths ${ }^{19}$; in some townships (with mainly Black residents) testing has picked up a faster spread of the virus in preparation for the second wave (Cotterill, 2020; Daniel, 2020). For example, Gauteng, the smallest but most populous province in South

\footnotetext{
17 ADD International: https://add.org.uk/whydisability?gclid=CjwKCAiApNSABhAIEiwANuR9YP5plkcWBqmWKTJmNPvxcY-kCzdyodFIXZw967jvUHHUvWOivpVWhoCjsoQAvD_BwE

${ }^{18}$ Coronavirus disease (COCVID-19) F\&Q - When should I get a test for COVID-19? 12 October 2020: https://www.who.int/emergencies/diseases/novel-coronavirus-2019/question-and-answers-hub/q-adetail/coronavirus-disease-covid-19

${ }^{19}$ WHO Coronavirus Disease (COVID-19) Dashboard: https://covid19.who.int/table
} 
Africa, has the highest number of tests,,$^{20}$ and the lowest proportion of adults living in poverty at $29.3 \% .^{21}$

Socio-economic status is a factor. The majority of COVID-19 tests have been completed in the private sector, however, people can get tested for free at state/public hospitals, community clinics, and some pharmacies. Bookings at private doctors/facilities, or at home for a premium fee, can be done online. Alternatively, pathology chains will all take samples at various centres around South Africa for testing - in some cases as a drive-through service (Daniel, 2020). However, this will exclude several minority groups. Some argue that the wealthier provinces in South Africa, like Western Cape ${ }^{22}$, are at an advantage over others in having the infrastructure required to an enable test, trace, and isolate (TTI) to be effective. Broadening the remit of TTI systems to go beyond COVID-19 alone offers an opportunity to positively engage with younger individuals with poor health-seeking behaviour, who might otherwise be unknown to public health or healthcare services (Jain et al., 2020). The youth (aged 18-34) constitute almost a third of the population (17.84 million) in South Africa, ${ }^{23}$ the majority are female and Black African. Levels of other health conditions such as HIV is also high in younger age women:

\section{Accessing COVID-19 treatment}

Migrants and refugees in Kenya, Somaliland, and Niger have reported suspicion and mistrust growing among the native-born population due to the belief that immigrants are bringing COVID19 to their countries (Mixed Migration Centre, 2020a). Interviews conducted with immigrants has highlighted their fear of facing racism and discrimination in accessing health services for COVID-19 (Mixed Migration Centre, 2020b). For example, an Ivorian woman in Tunisia stated that migrants would refrain from going to the hospital if they had a cough due to the fear of further stigmatisation. Immigrants in Tunisia also fear that government authorities may prioritise Tunisian citizens over immigrants in providing healthcare services, especially in cities with significant immigrant and refugee populations.

\section{Case study: South Africa}

Until now, South Africa has not used any COVID-19 vaccine. Interim results from a Novavax vaccine trial that ran separately in South Africa where the B.1.351 (sometimes referred to as $501 Y . V 2)$ variant of COVID-19 has accounted for most infections, found that its efficacy dropped from $60.1 \%$ to $49.4 \%$ when HIV-infected participants were included. ${ }^{24}$ People living

\footnotetext{
20 With 370,264 confirmed positive test cases as of 21 January 2021:

https://www.statista.com/statistics/1108670/coronavirus-cumulative-cases-in-south-africa/

${ }^{21}$ Five facts about poverty in South Africa - data from The Living Conditions Survey (LCS): http://www.statssa.gov.za/?p=12075

22 According to the latest census the Western Cape population is approximately half (49\%) formerly classified as coloured (mixed race); 33\% as "Black African", 17\% "White", and 1\% "Indian or Asian". There is a long-standing feeling among some that in an effort to redress the problems from the past, the democratic government has ignored their needs. Race in South Africa: 'We haven't learnt we are human beings first'. 21 January 2021- see https://www.bbc.co.uk/news/world-africa-55333625

23 Statistics South Africa: http://www.statssa.gov.za/?p=12362

24 Wadman M, Cohen J (2021). Novavax vaccine delivers 89\% efficacy against COVID-19 in U.K.-but is less potent in South Africa. 28 January 2021: https://www.sciencemag.org/news/2021/01/novavax-vaccine-delivers89-efficacy-against-covid-19-uk-less-potent-south-africa
} 
with HIV/AIDS (PLWHA) are at high risk of COVID-19 if they do not have access to anti-retroviral treatment (ART). ${ }^{25}$ South Africa has the largest number of people on ART worldwide. ${ }^{26}$

In January 2021, South African authorities approved the use of a drug used to control parasites in humans and livestock to treat COVID-19 patients. The Ivermectin drug will not be limited to patients with known COVID-19 co-morbidities. However, Ivermectin will only be used in a "compassionate controlled-access programme", amid drug trials. This will help the regulator to monitor its use and collect much-needed safety data (Kew, 2021). However, the roll-out of the controlled-access programme has been considered "ethically unjust" by some doctors. ${ }^{27}$

\section{Impacts of these challenges on excluded and marginalised groups}

COVID-19 has had a disproportionate impact on racial and ethnic groups in high income countries. ${ }^{28}$ However, there is a lack of similar data from LMICs. A recent systematic review of social inclusion and urban access to healthcare in LMICs found limited consideration to intersectional aspects of social inclusion, such as gender, ethnic and religious backgrounds, disability, migration status, and age (Mirzoev and Tull et al., in preparation). However, there is no clear evidence to confirm or rule out an association between ethnicity and outcome in COVID19 is important for regions such as Africa and South Asia, where the pandemic is at an earlier stage (Khunti et al., 2020). More research is needed to better understand the impact that COVID19 has on Black, Asian, and minority ethnic (BAME) communities (Abuelgasim et al., 2020). The following section illustrates that the majority of research shows that impacts on marginalised or excluded groups are negative:

\section{Hard-to-reach populations}

These people are also known as high risk or marginalised populations. They suffer from a number of supply-side barriers to vaccination, including geography, war and conflict, homebound mobility limitations, or inadequate vaccination systems (Ozawa et al., 2019). Evidence shows an overall negative impact of COVID-19 for groups in a range of social areas:

\section{Disrupted access to healthcare services}

Barriers to migrants' access to healthcare include issues with GP registration, uncertainty about healthcare and migrants' legal status, financial concerns, cultural issues, and clashes with staff. If this exclusion continues during the COVID-19 epidemic, it will promote a hostile environment for "low skilled" migrants, resulting in the wrongful denial of health services to thousands (Dodds \& Fakoya, 2020).

\footnotetext{
${ }^{25}$ AVERT - CORONAVIRUS (COVID-19) AND HIV: https://www.avert.org/coronavirus/covid19-HIV

${ }^{26}$ AVERT - HIV AND AIDS IN SOUTH AFRICA (2019): https://www.avert.org/professionals/hiv-aroundworld/sub-saharan-africa/south-africa

${ }^{27}$ Comins L (2021). SA doctors livid over Sahpra's guidelines for Ivermectin use. 29 January 2021: https://www.iol.co.za/mercury/news/sa-doctors-livid-over-sahpras-guidelines-for-ivermectin-use-6fac05da-f64d4fcd-a5e0-af2ae7fba4ff

${ }^{28}$ For example, in the USA: https://doi.org/10.1093/cid/ciaa815
} 
Homeless people are at particular risk from co-morbidities such as tuberculosis. However, the impact of the COVID-19 response on care-seeking behaviour among people with tuberculosis is unknown. Available data suggests that fewer people are accessing tuberculosis services than would usually be expected during the COVID-19 response worldwide, ${ }^{29}$ including in India ${ }^{30}$ and South Africa. ${ }^{31}$ COVID-19 is also likely to reduce access to tuberculosis diagnostics.

LQBTQI patients not able to receive hormone therapy for gender dysphoria could result in higher levels of mental distress, depression, anxiety or suicidal ideation (Crank, 2020).

\section{Adverse health outcomes}

Refugees, as well as displaced, undocumented, and stateless people around the world would remain vulnerable to COVID-19 if they remain ineligible for inoculations. ${ }^{32}$ They will be more likely to suffer physical and mental health as consequence (Mukumbang, 2020). Such disproportionate impact warrants them to be considered a "most-at-risk" population.

Migrants and refugees are also particularly vulnerable to the impact of COVID-19 in the wider community (Kluge et al., 2020). As these populations are mobile, additional risk of COVID-19 spread will occur, unless they are included in vaccination efforts (IRC, 2021).

Sex workers are among the most marginalised hard-to-reach groups (Platt, 2020). Sex workers who are homeless, use drugs, or are migrants with insecure legal or residency status face greater challenges in accessing health services (Kluge et al., 2020).

PLWD are more likely to experience increased health needs and worse health outcomes; these issues are likely to be intensified during the COVID-19 epidemic (Armitage \& Nellums, 2020 and Kuper et al., 2020 in McKinney, 2020). People with learning disabilities are more likely to have other physical health problems, such as obesity and diabetes (Burgess et al., 2020). Certain kinds of learning disability, such as Down's syndrome, can make people more vulnerable to respiratory infections, which can increase their risk of dying from COVID-19 (Public Health England, 2020):

\section{Case study: Uganda}

According to the 2002 Population and Housing Census, at least $16 \%$ of the population are PLWD. Recent research shows that COVID-19 has resulted in limited or absent access to medical services and medication for disabled adults and children with chronic illness (Mbazzi et al., 2021). This can be due to restrictions in travel, some facilities restricting access (to care or information on care), and limited financial resources. Data from the International Disability

\footnotetext{
${ }^{29}$ Louie JK, Reid M, Stella J, et al. (2020). A decrease in tuberculosis evaluations and diagnoses during the COVID-19 pandemic. Int J Tuberc Lung Dis, 24: 860-862: https://doi.org/10.5588/ijtld.20.0364

${ }^{30}$ Gupta A, Singla R, Caminero JA, et al. (2020). Impact of COVID-19 on tuberculosis services in India. Int J Tuberc Lung Dis, 24: 637-639: DOI: 10.5588/ijtld.20.0212

${ }^{31}$ National Institute for Communicable Diseases. Impact of COVID-19 intervention on TB testing in South Africa: https://www.nicd.ac.za/wp-content/uploads/2020/05/Impact-of-Covid-19-interventions-on-TB-testing-in-SouthAfrica-10-May-2020.pdf

32 Debinski G (2021). Vaccine politics and human rights. 13 January 2021: https://www.gzeromedia.com/vaccinepolitics-and-human-rights
} 
Alliance persons with albinism (lack the gene to produce melanin) in Jinga, eastern Uganda are often not regarded as PLWD, and as a consequence they are left behind in health programmes. Their requirements are hardly considered, even in non-emergency settings (IDA, 2020). A main impact is that risk of skin cancer for this group increases.

\section{Socio-economic inequalities}

Refugees, as well as displaced, undocumented, and stateless people are also more likely to suffer disproportionate socio-economic consequences of COVID-19 (Mukumbang, 2020). These groups have been largely excluded from social protection and resources needed to minimise their contracting COVID-19 (Burgess et al., 2020). The increasing economic and financial woes of the certain countries have led to governments adopting and frequently changing laws that, in many ways, have impacted negatively on the lives of these foreign-born migrants (Mukumbang et al., 2020).

In the longer term, the impact of sex workers not being vaccinated for COVID-19 would result in negative economic impacts (Kluge et al., 2020). This can affect different genders and age groups.

\section{Hard-to-vaccinate populations}

Examples of these populations are those who are reachable but difficult to vaccinate. This can be due to distrust, religious beliefs, lack of access to available vaccination services, or genderbased discrimination (Ozawa et al., 2019):

\section{Disrupted access to healthcare services}

When healthcare systems are overburdened and resources are reallocated to respond to the COVID-19 pandemic, this can further disrupt health services unique to the well-being of women and girls (UN Women, 2020: 10). The health of women generally is adversely impacted through the reallocation of resources and priorities, including sexual and reproductive health services (UN Women, 2020: 2). This can make it more difficult for women and girls to receive treatment and health services, especially higher risk groups such as pregnant women/girls, and those living with HIV, and/or PLWD. The impact of lower access to health services can be higher unintended pregnancies in women and girls (Rafaeli \& Hutchinson, 2020). Lower access to water, sanitation and hygiene (WASH) will also facilitate spreading COVID-19 to other vulnerable groups.

\section{Adverse health outcomes}

Despite the risk of complications and poor perinatal outcomes, pregnant women are not recognised as a high-priority group for COVID-19 vaccination. ${ }^{33}$ The health impacts can be catastrophic, especially in rural, marginalised and low-literacy communities, where women are

33 WHO SAGE roadmap for prioritizing uses of COVID-19 vaccines in the context of limited supply. Version 1.1. Nov 13, 2020. World Health Organization, Geneva 2020. 
less likely to have access to quality, culturally accessible health services, essential medicines, or insurance coverage. This may also result in more child mortality.

According to UNICEF: "Not only are children and young people contracting COVID-19, they are also among its most severely impacted victims. Unless we act now to address the pandemic's impacts on children, the echoes of COVID-19 will permanently damage our shared future." 34 Vaccinating children is likely to have benefits both direct (protecting children against rare severe paediatric cases of COVID-19 and post-infectious conditions such as multi-system inflammatory syndrome in children [MIS-C]), and indirect (protecting others by reducing spread) (Klass \& Ratner, 2021).

Older people, especially those $\mathbf{6 5}$ years old and above who have comorbidities, will have an increased admission rate into the intensive care unit (ICU) and mortality if they become infected with COVID-19 (Sanyaolu et al., 2020).

LGBTQI patients are more likely than the general population to be smokers, which could compromise their lungs, and make it more difficult to recover from a respiratory illness if they are not vaccinated for COVID-19. The impact of not being vaccinated for COVID-19 would increase sex workers' vulnerability to poor health outcomes (Kluge et al., 2020). Data from India shows that people living with HIV/AIDS (PLWHA), including LGBTQI people, struggled to access their medication. Their points of medication distribution and medical attention have typically been government-designated as COVID-19 centres, meaning that immunocompromised people would be taking extra risks to go there to collect medication. ${ }^{35}$

There is limited data and evidence on the impacts of COVID-19 on PLWD with pre-existing health conditions (Rafaeli \& Hutchinson, 2020).

\section{Socio-economic inequalities}

COVID-19 does not discriminate, it can affect rich and poor. However, the impact of COVID-19 on livelihoods is gendered. Vaccine uptake impacts women's economic and personal security (Harman et al., 2020). Being indoors due to 'lockdowns'36 might prevent the disease from spreading, but lack of income and lack of food will very likely pose a much greater threat to life and wellbeing (Pesa, 2020). In sub-Saharan Africa, research shows that secondary impacts of COVID-19 on women include lack of social protection, land rights, food security and nutrition, and lower numbers of female health workers (Rafaeli \& Hutchinson, 2020). This can result in higher poverty. For example, in South Africa, women (especially those in informal employment)

\footnotetext{
34 UNICEF - DON'T LET CHILDREN BE THE HIDDEN VICTIMS OF COVID-19 PANDEMIC: https://www.unicef.org.uk/press-releases/dont-let-children-be-the-hidden-victims-of-covid-19-pandemic-unicef/ 35 Submission from the Submission by Human Rights Watch, in OHCHR (2020e) Protection against violence and discrimination based on sexual orientation and gender identity (pp. 10/25).

36 'Lockdowns' are an example of a measure which might be effective in wealthy European urban areas, where people can easily stock up on a week's worth of food, and where temporarily unemployed workers can fall back on state benefits. Due to international pressure the same measure is being touted in African countries. But a tomato vendor in a South African township does not have the same opportunities to 'stay at home' to 'flatten the curve'. Being indoors due to 'lockdowns' might prevent the disease from spreading, but lack of income and lack of food will very likely pose a much greater threat to life and wellbeing (Pesa, 2020).
} 
have already suffered severe economic, livelihood, and social impacts from the lockdown that was imposed to curb the spread of the virus. ${ }^{37}$

Breastfeeding women have been excluded from the Pfizer ${ }^{38}$, AstraZeneca and Moderna vaccine trials, even if they are otherwise eligible (for example if they are a frontline health, social care worker, or a residential home carer). ${ }^{39}$ This could result in wider socio-economic impacts for women.

Rafaeli \& Hutchinson (2020) found that girls' education, and informal employment in subSaharan Africa have all been affected by COVID-19. The "indirect" impact of lack of vaccination in children will increase their family toll of parental illness, failing economies, and chronic stress (Klass \& Ratner, 2021). As a result of COVID-19, older women tend to face lower life incomes and also lower pensions, with fewer possibilities to access care for themselves (UN Women, 2020: 14).

Historically, minorities and indigenous peoples make up a large share of the workforce in the informal sector, with women disproportionately represented (UN, 2018 in Al Saba, 2020: 9). There is limited evidence for indigenous peoples, particularly those from smaller or more isolated communities (Al Saba, 2020: 3). However, data on minority indigenous people shows that not only can they not access up-to-date information about the situation the world is in, they cannot afford health clinic fees. Due to COVID-19 lockdown, where everything is locked down including all businesses, cheap labour is not always required, resulting in poverty and food insecurity. ${ }^{40}$

\section{Social exclusion and violence}

LGBTQI people are among the most vulnerable and marginalised in many societies, and among those most at risk from COVID-19. ${ }^{41}$ COVID-19 has a disproportionate impact on LGBTQI persons: "with few exceptions, the response to the pandemic reproduces and exacerbates the patterns of social exclusion and violence" (OHCHR, 2020c: 4/25; OHCHR, 2020d).

\section{Lessons learned from previous pandemics and vaccine roll-out}

There are potential factors, such as coverage for certain groups, that may never have been fully studied in relation to mass immunisation campaigns and, therefore, do not appear in any literature (published, unpublished, or grey literature) (Weiss et al., 2009: 364). Africa has good

\footnotetext{
37 The National Income Dynamics Study - Coronavirus RApid Mobile (NIDS-CRAM) survey: https://cramsurvey.org/reports/

38 However, In November 2020, Pfizer/BioNTech vaccine revised its guidance so that pregnant and breastfeeding women can now receive the COVID-19 vaccine.

39 Hare H, Womersley K (2020). Healthcare workers who breastfeed should be offered the covid-19 vaccine. BMJ. 21 December 2020: https://blogs.bmj.com/bmj/2020/12/21/healthcare-workers-who-breastfeed-should-beoffered-the-covid-19-vaccine/

40 United Organisation for Batwa Development in Uganda (UOBDU) (2020). Increased hunger and poverty among the Batwa amidst COVID-19 in Uganda. Forest People's Programme. 7 May 2020: https://www.forestpeoples.org/en/increased-hunger-and-poverty-for-Batwa-in-Uganda-amid-covid-19 ${ }^{41}$ Bachelet M (2020): COVID-19: Targeted actions needed to protect LGBTI people amid pandemic: https://www.ohchr.org/EN/NewsEvents/Pages/DisplayNews.aspx?NewsID=25807\&LangID=E
} 
experience from its established vaccination campaigns, including using vaccines to counter outbreaks such as Ebola and HIV/AIDS; examples can also be taken from eradication of polio, measles vaccination programmes, and 2009 H1N1 (swine 'flu) influenza outbreak. Although there is not a Zika vaccine, lessons can also be learned on acceptability research from the Zika international emergency in 2015:

\section{Evidence from research on previous pandemics}

Research from Ebola vaccine clinical trials and vaccination campaigns by the Ebola Vaccine Deployment, Acceptance and Compliance (EBODAC) consortium shows that vaccine roll-out programmes can be successful. This guidance has been used in several different vaccination programmes in order to aid with social inclusion:

\section{Communication (to address misinformation)}

\section{Build local vaccine acceptability and confidence to prevent threats to roll-out}

In 2015, the Vaccine Confidence Project developed the Vaccine Confidence Index (VCI): a survey tool used to monitor spatiotemporal trends in vaccine confidence at national and global levels (de Figueiredo et al., 2020). De Figueiredo et al. (2020) found a link between religion and uptake when exploring barriers to vaccine uptake: the minority religious groups (or those refusing to provide their religious belief) who were associated with lower probability of uptake (de Figueiredo et al., 2020: 905).

Ebola: DR Congo's experience holds vital lessons in distributing the vaccine and gaining the trust of those receiving it (Holland, 2020). A second experimental vaccine (Johnson \& Johnson, 2dose course, given 8 weeks apart) was introduced in DR Congo as an additional tool to extend protection against the 2018 virus outbreak - but not until 2019, and only in areas which did not have "active Ebola transmission" (Child, 2019). The first (Merck) vaccine, estimated to be $97.5 \%$ effective, required a single shot. The differing dosing schedules could have eroded already fragile trust in response efforts and be difficult to implement in eastern DR Congo, where there are large numbers of displaced people and much of the population is highly mobile. A toxic mix of deep-rooted insecurity in the region, widespread mistrust over the outbreak, and response efforts significantly hampered the bid to halt the spread of the virus. Close collaboration with the local government to obtain mutual trust were keys to success in minority group research in the DR Congo (Haug, 2018). Community liaison and social science teams can also worked with clinical teams to strengthen trust, as they did in Sierra Leone (Dada et al., 2019).

Measles \& Rubella: Vaccination campaigns have offered relevant insights, e.g. about parents' decisions regarding vaccinating children they do not believe are at serious risk; as well as about trust, access, and equity (Klass \& Ratner, 2021). Gavi supported a mass vaccination MeaslesRubella Campaign (MRC) in Bangladesh during January-February 2014. The Expanded Program on Immunization developed a variety of information, education and communication (IEC) materials that were used from the national level to the community level. 
Polio: Campaigns have revealed that vaccine acceptance by communities was threatened by anti-vaccination movements, conspiracy theories, miscommunication, religious dogma and rumours (Rahi \& Sharma, 2020). The Global Polio Eradication Initiative (GPEI), a publicprivate partnership, led the knowledge efforts to eradicate polio. It worked to ensure that communities and individual caregivers were provided with facts about polio and polio vaccination, to combat the spread of health misinformation, and ensure that communities and caregivers were equipped with the knowledge they need (Mogoathe, 2020).

Zika awareness: Healthcare workers as community champions were not the only source of hope; trust in religious doctrine (an external lever of trust), and caregiver groups (networks of trust) also played important roles. In particular, WhatsApp was an important means of information diffusion, but only within social networks of trust. Information trust was usually high but depended on source (Simas et al., 2020: 959). ${ }^{42}$

\section{Effective community engagement for vaccine roll-out (reciprocity, dialogue, and respect)}

Hard-to-vaccinate populations, or individuals facing demand-side barriers to vaccination, need better ways to make vaccines acceptable. Community-based education programmes may be carried out to raise awareness, reduce distrust, or involve religious leaders to accommodate vaccination. Incentives can be deployed to increase the use of vaccination among individuals with socio-economic hardship or debilitating time constraints preventing vaccination (Ozawa et al., 2019):

Ebola: The situation in eastern DR Congo was unique: a public health emergency of international concern in the middle of a conflict zone marked by weak governance, community violence, and forced displacement (Bisca \& Bance, 2019). Most people refused to seek help in Ebola Treatment Centres due to misinformation about root causes of the disease, and the supposedly occult intentions of responders - an estimated $68 \%$ of community deaths occurred in private homes in 2019, although this decreased to $29 \%$ in the $11^{\text {th }}$ outbreak in 2020 (WHO, 2020b). ${ }^{43}$ As these community deaths also posed a major transmission risk, it was no wonder that several actors asked public health responders to put communities front and centre in the Ebola response. ${ }^{44}$ Listening to community voices is a good start, but for outreach efforts to be effective, consultations with local leaders should translate into tangible improvements in people's lives (Bisca \& Bance, 2019).

\section{Understand 'communities' and 'marginalisation' in social dynamics}

Ebola: In healthcare, populations or social groups with lower health status - associated with social, environmental, biological and/or political determinants of health - are frequently termed

\footnotetext{
42 However, cultivating hope can, paradoxically, have an adverse impact on healthcare service delivery. Associated social impact was found by Simas et al. (2020: 955-956): rejection of clinical diagnosis if they are negative; and caregivers of children putting more trust in professionals who offer hope, even if unrealistic. 43 WHO (2019). Ebola virus disease - Democratic Republic of the Congo. 16 May 2019. World Health Organization: https://www.who.int/csr/don/16-may-2019-ebola-drc/en/ ; 18 November 2020: https://www.who.int/csr/don/18-november-2020-ebola-drc/en/

${ }^{44}$ Muvudi M (2019). Community involvement is key to eradicating Ebola. 27 February 201. World Bank Blog: https://blogs.worldbank.org/health/community-involvement-key-eradicating-ebola
} 
'marginalised', 'vulnerable' or 'underserved'. There are numerous tensions between these notions in the literature (Shelley-Egan \& Dratwa, 2019). Using the term 'communities' in an uncritical and unreflective way threatens to obscure some of the lessons learned from Ebola (Wilkinson et al., 2017). In the Ebola response, the use of the term 'community' by public health agencies - and in the representations of some of those who came forward as "community leaders' - glossed over a large range of more salient forms of identity, hierarchy and division in social life in the Mano River region, which includes Côte d'Ivoire, Guinea, Liberia and Sierra Leone. These include gender, in a region where questions of health and sickness are intimately bound up with distinct masculine and feminine realms of knowledge, practice and authority, underpinned by gender-specific initiation societies (Wilkinson et al., 2017). Therefore, the lesson is not that 'communities' can stop epidemics and build trust; it is that understanding social dynamics is essential to designing robust interventions and should be a priority in public health and emergency planning (Wilkinson et al., 2017).

\section{Prevent miscommunication with help from the correct community talent}

Ebola: The capacity of 'community leaders' or 'community health workers' to work across ethnic, religious and socio-economic boundaries is often ill-founded, especially when their efforts are not remunerated (Wilkinson et al., 2017).

Social and political relationships need to be taken into account. For example, Kissi, an ethnic group from the forest region of Guinea has long running experiences of marginalisation and abuse at the hands of whites and other ethnicities (Wilkinson et al., 2017). A system of village chiefs and then district officials had been put in place under colonial times, of which people were deeply distrustful. Various response partners trying to contain the epidemic had identified 'community leaders' to liaise between them and the 'community', however, there was consistent and sometimes violent rejection of outside help. Therefore, by asking residents from 26 villages who they would trust and nominate to speak on their behalf, a more relevant and respected selection was made (including traditional practitioners, heads of the sacred forests, religious leaders - Christians and Muslims -, circumcisers, village birth attendants, hunters, youth, returned migrants from the city, and elders/older poeple), allowing this Ebola sensitisation strategy to be a success.

\section{Understand social impact on livelihoods}

Ebola: Quarantines have had a disproportionate impact on hard-to-reach groups such as the

older people, the poor, and people with chronic illness or disability (Rohwerder, 2014). For example, the experience of women in Liberia during the Ebola outbreak demonstrates the heavier impact on women, especially those working as market traders (Burki, 2020 in Al Saba, 2020: 9).

\section{Compliance management (supported by innovative technology approaches)}

Vaccine compliance management ensures that the targeted are the ones receiving the vaccination. In case of a two-dose vaccine, it ensures that those who received the first dose are the ones who receive the second dose at the right time. Supply and demand have been measured in a variety of ways: 


\section{Develop and implement innovation in health systems to identify vulnerable groups}

Ebola: Bedford's (2018b: 4) review of lessons learned from health seeking behaviour during the Équateur outbreak of 2018 suggests that any future responses using the vaccine should study "perceptions and experiences of the vaccine (as an intervention, its trial status, and how it was introduced and rolled-out, i.e. as a ring vaccination) must be carefully documented... after the outbreak is declared over." The Special Populations Assessment Tool from the US Centers for Disease Control and Prevention (CDC) can be used as "may help in identifying those groups of individuals who require differing messages from the general public information message or who cannot be reached through mass communication channels." 45

Technology can enable countries to track and demonstrate the progress of their vaccination programmes and ultimately provide a foundation for re-organising the health system.

Electronic or digital vaccine registries are a particularly promising tool. They can ensure equitable access by identifying sections of communities with limited access to the vaccines. There are already a number of African-created and international apps and registries under development (Blair in Sisay et al., 2020). For example, a Social Vulnerability Index using census and household survey data, when displayed spatially at a sub-county level, may help highlight the location of the most vulnerable households and populations (Stanturf et al., 2015).

Active case finding and contact tracing activities played a major role in controlling the 2014-2016 Ebola epidemic, which devastated communities in West Africa. ${ }^{46}$ However, disease surveillance was consistently challenged by low levels of reported alerts, particularly among deaths in DR Congo. Despite these challenges, multi-sectoral co-ordination was strengthened, and surveillance and investigation activities were enhanced (WHO, 2020b).

Those working in/with the programme also need to be managed: for example, the WHO struggled to trace and vaccinate health workers who operated small, unregistered facilities scattered throughout the forests of the eastern DR Congo (Maxmen 2019). The EBODAC Gap Analysis Tool checks for capacity building of staff and stakeholders include specific trainings in Communication, Community Engagement and Compliance Management (3C) for Ebola vaccine deployment for special cadres or groups. ${ }^{47}$ These "special groups" include traditional healers, which may pose a high risk of contracting and passing on the disease, so these need to be included in the compliance management (Sisay et al., 2020: 11).

Measles: Two different surveillance systems in South Africa enabled the 1996-1997 campaign to reach children who had not previously been vaccinated (i.e. the 'hard to reach'), especially in Mpumalanga where Blacks/Africans represent the largest ethnic group (89\%) (Uzicanin et al., 2002). In response to the 2004 outbreak in Liberian refugees, two mass vaccination campaigns targeting children aged between 6 months and 15 years were held at all 19 transition camps

\footnotetext{
${ }^{45}$ CDC CERC. Crisis \& Emergency Risk Communication (CERC) Special populations assessment (pp.1): https://emergency.cdc.gov/cerc/resources/pdf/specialpopulationsassessment.pdf 462014 Ebola Outbreak in West Africa-Reported Cases Graphs 2016:

https://www.cdc.gov/vhf/ebola/outbreaks/2014-west-africa/cumulative-cases-graphs.html

${ }^{47}$ EBODAC (2019). EBOLA VACCINE COMMUNICATION, COMMUNITY ENGAGEMENT AND COMPLIANCE MANAGEMENT (3C) GAP ANALYSIS TOOL. "Special cadres or groups" may include: the media, armed forces, community influencers, traditional healers, burial groups, cross border stakeholders, etc.(pp.87): https://www.worldvision.ie/sites/worldvision.ie/files/pdf/EBODAC-3C-Gap-Analysis-Tool.pdf
} 
(TCs) in Côte d'Ivoire (Kouadio et al., 2009). In addition to monitoring average vaccination coverage statistics, metrics of spatial heterogeneity (i.e. uneven distribution within an area) was used to determine the success of immunisation programmes, as well as risk of disease persistence (Brownwright et al., 2017). For displaced populations, a Diseases Surveillance Team (DST) was established to perform active surveillance in order to detect cases of rash or fever in the early phase, and to take timely control action.

\section{Use surveillance systems from other vaccination roll-outs for vulnerable groups}

Nationally or regionally integrated vaccine information tracking systems could help improve vaccination coverage for people who move around (e.g. migrants or nomadic groups), or for individuals who are not consistently receiving health care provider recommendations (Ozawa et al., 2019):

Polio: GPEI had an extensive testing strategy that used community and family engagement, science and research, as well as its own control systems. One of them was district microplanning ${ }^{48}$ priority plans using current health facility data, which was key in reaching remote and high-risk populations. This strategy has helped keep India polio-free for five years. GPEl's teams in Nigeria, meanwhile, used polio surveillance systems that identifed new cases and where they originate (Mogoatlhe, 2020). Existing female health workers in particular played a critical role in this effort: they travelled by every form of transportation imaginable to reach children in remote locations and from mobile populations, and figured out how to reach children in regions rife with conflict and insecurity (Ghai, 2021).

Measles \& Rubella: The Mewat District of north-western India is also using microplanning to increase its rates of vaccination against measles and rubella. ${ }^{49}$

\section{Regular testing and sampling to identify priority groups}

H1N1 swine 'flu: If members of the public at high risk of death from influenza are prioritised for vaccination, then proportionate supplies of vaccine were distributed according to incidence of risk factors, such as certain chronic illnesses. By contrast, if vaccine was distributed in amounts proportional to area population rather than to risk, priority groups may not have been reached as needed (DeBruin et al., 2012).

Polio: In order to help prevent massive outbreaks, GPEI and its partners established sampling sites in areas that are prone to outbreaks (Mogoatlhe, 2020). Environmental surveillance, which involves testing sewage or other environmental samples for the presence of poliovirus, helped confirm polio cases in the absence of symptoms like acute flaccid paralysis (AFP)..$^{50}$ Doctors and health care workers in high-risk areas regularly tested children, while local governments tested water sources like rivers for polio-causing bacteria.

\footnotetext{
48 WHO-UNICEF (2009). Microplanning for Immunization Service Delivery - Using the Reaching Every District (RED) Strategy: https://www.who.int/immunization/sage/9_Final_RED_280909.pdf

49 Global Polio Eradication Initiative (2019). Five ways the fight against polio is a fight against other diseases. 10 May 2019: https://polioeradication.org/news-post/five-ways-the-fight-against-polio-is-a-fight-against-otherdiseases/

50 Garcia D (2019). 5 ways our work against polio fights other diseases. 17 April 2019. Rotary:

https://www.endpolio.org/5-ways-our-work-against-polio-fights-other-diseases
} 


\section{Collaboration}

Collaboration between the private sector, academia, government, and civil society is also important (Sadlier, 2020):

\section{Awareness of positive and negative outcomes in collaborations}

Measles \& Rubella: The government included village elders and religious preachers to achieve success in Mewat, north east India, to quash rumours that the vaccination would make children sterile. By the time the eight-week programme came to an end, $99.01 \%$ of the state target was achieved. ${ }^{51}$

\section{Involve surrounding communities in public health interventions}

Measles: As refugee camp residents may visit neighbouring villages or other camps (i.e. Tanzania Kibondo District camp had a central health facility that is used by residents of the camp and surrounding villages), extending the programme for both refugees and non-camp residents from surrounding areas was crucial in preventing further outbreaks (Kamugisha et al., 2003).

\section{Establish social relationships with communities}

Ebola: A critical step is to begin with a more realistic account of local social relationships. Including anthropologists with specialist knowledge of people and contexts in policy formation and implementation can assist this process. A 'one size fits all' approach and public meetings with supposed key stakeholders is not enough. To achieve the post-Ebola aims of a trusting public and strong resilient health systems, more nuanced approaches were needed, which were sensitive to how social, political and economic interests interact in policy processes and local settings (Wilkinson et al., 2017).

Measles \& Rubella: Additionally with IEC materials, the EPI held advocacy meetings with Bangladesh Medical Association (including with renowned medical professionals), and the Pediatric Association, to advise them of the MRC and to seek their support, including for disseminating information to parents (Sarma et al., 2019). Confirmed measles incidence decreased $82 \%$, including in hard-to-reach populations. ${ }^{52}$

\section{Use multiple local logistical options to hard-to-reach groups}

Ebola: The WHO used only local DR Congo healthcare workers to distribute the vaccine in a subsequent outbreak in the west, which ended in six months with 55 deaths (Holland, 2020). Between 2018-20, health workers inoculated more than 400,000 people in three Ebola outbreaks in DR Congo, carrying vials colder than an Antarctic winter (60-80 degrees Celsius) across warm forests, and along mud-clogged mountain roads. When cars could not pass (i.e. due to roads

\footnotetext{
${ }^{51}$ Quelling rumours to immunise children in Mewat. 14 December 2018: https://www.hindustantimes.com/indianews/quelling-rumours-to-immunise-children-in-mewat/story-zB2MiY88o26mVjfabQIJCO.html

${ }^{52}$ Khanal S, Bohara R, Chacko S, et al., (2017). Progress Toward Measles Elimination — Bangladesh, 2000_ 2016. Weekly / July 21, 2017 / 66(28);753-757: https://www.cdc.gov/mmwr/volumes/66/wr/mm6628a3.htm
} 
without bridges flooded), they drove motorbikes. If water was the only way, they used canoes (Holland, 2020).

\section{Lessons learned for COVID-19 vaccine roll-out strategies}

Achieving global, equitable access to COVID-19 vaccines and therapeutics will be difficult (Bollyky et al., 2020). The challenge with a prioritised distribution scheme relates to the need for data to guide distribution (DeBruin et al., 2012: 588). Roll-out of the COVID-19 vaccine is likely to be unique by prioritising adults over children (Blair in Sisay et al., 2020: 8). Based on previous pandemics, plans are beginning to emerge for ensuring the equitable worldwide distribution of COVID-19 vaccines and therapeutics resulting from biomedical innovations:

Speed of vaccination is important in curtailing COVID-19:

The WHO was heavily criticised for its "sluggish" response to the August 2018 Ebola outbreak (the second worst in recorded history in the DR Congo) 13 months after the outbreak (Child, 2019).

Not all traced people will be vaccinated:

Findings from the Proceedings of the National Academy of Sciences of the United States of America (PNAS) report (Wells et al., 2019: 10180; Lenhardt, 2020) assumed that all contacts identified in contact tracing in the DR Congo Ebola outbreak were vaccinated, although in practice the vaccination is only administered to those over the age of 18 years and not pregnant, breastfeeding, or severely ill, which indicates limitations of vaccination for certain vulnerable groups, as well as only those who consent to the vaccination.

Combined ring and community vaccination strategies can be successful:

MSF stated that the WHO's vaccination strategy no longer made sense because tracing contacts of people with Ebola has proven so difficult. $20 \%$ or more of close contacts could not be reached or refused vaccination (Chowell et al. 2019). Around half of all people diagnosed with Ebola during the 2018 outbreak were not identified as contacts of the sick before they themselves became ill - and so never received the vaccine (Child, 2019). Therefore, a "third ring" communitylevel vaccination that targeted members of communities even if they are not known contacts of Ebola cases was needed (Chowell et al. 2019). MSF recommended that Ebola responders should instead vaccinate the population widely in Beni, north eastern DR Congo, and other areas where Ebola has spread for months (Maxmen, 2019). Therefore, if levels of inaccessibility exceed approximately $10 \%$ in the context of significant delays to vaccinating contacts, a combined ring and community vaccination strategy is effective until the levels of inaccessibility exceed approximately 50\% (Chowell et al. 2019).

\section{Expand categories of at-risk groups}

Consider including eligible pregnant women and children:

There is currently no evidence that the COVID-19 vaccine is unsafe during pregnancy. Both Pfizer and Moderna recently began new vaccine trials including children as young as age 12 years old. 
Pregnant women represent a vulnerable group, often overlooked during epidemics, as recently seen during the Ebola outbreaks. During the Ebola epidemic in Sierra Leone, fewer pregnant women accessed healthcare, and among those who did there were increased rates of maternal mortality and stillbirth. In DR Congo, to direct women to places which were not seen as an infection risk, libraries and schools were repurposed to offer maternal health services during its recent Ebola epidemic (Burki, 2020). The programme in DR Congo was approved for expansion to younger age groups in the first half of $2019,{ }^{53}$ as both UNICEF and Save the Children found that children were more likely to die from the disease than adults. ${ }^{54}$

Donated $\mathrm{H} 1 \mathrm{~N} 1$ vaccination population coverage varied from $0.4 \%$ to $11 \%$, with a median coverage of $4 \%$. However, all countries targeted pregnant women $(21 \%$, range, $4 \%-72 \%)$ and healthcare workers $(9 \%$, range $1 \%-73 \%)$. Fourteen of 19 countries targeted persons with chronic conditions, and 10 of 19 countries vaccinated children (Mihigo et al., 2012).

\section{Prevent maternal mortality and morbidity and stillbirth}

Healthy women of childbearing age, newborn babies and infants are generally considered to be less severely affected by COVID-19 than other age groups. The debate over COVID-19 vaccines has (rightfully) focused on discovery and development, vaccine hesitancy, and equitable access (Harman et al., 2020):

Past pandemics have shown increased rates of maternal mortality and morbidity, adolescent pregnancies, and HIV and other sexually transmitted diseases. Multiple and intersecting inequalities, such as ethnicity, socio-economic status, disability, age, race, geographic location and sexual orientation, among others, can further compound these impacts (UN Women, 2020; 10).

During the Ebola epidemic in Sierra Leone, fewer pregnant women accessed healthcare, and among those who did there were increased rates of maternal mortality and stillbirth (Burki, 2020). In DR Congo, pregnant and lactating women were initially excluded from the Merck EVD vaccine compassionate use protocol used in North Kivu, out of concerns that women could spontaneously abort or that infants could be harmed. Some of the excluded women were highrisk contacts, but were not permitted to receive the vaccine, despite operational research showing that they understood the risks and would prefer to be given the choice about whether to take the vaccine (Rohan \& McKay, 2020).

\section{Continue child vaccination programmes}

There is a real threat of vaccine-preventable disease outbreaks because of COVID-19 related disruptions to routine immunisation (IRC, 2021):

\footnotetext{
53 ReliefWeb Report (2019). UNICEF DR Congo Ebola Situation Report North Kivu and Ituri-03 February 2019: https://reliefweb.int/report/democratic-republic-congo/unicef-dr-congo-ebola-situation-report-north-kivu-and-ituri03; llunga Kalenga O, Moeti M, Sparrow A, et al. (2019). The Ongoing Ebola Epidemic in the Democratic Republic of Congo, 2018-2019. The New England Journal of Medicine, Epub 2019/05/30. 54 DRC Ebola impact getting worse for children. 7 August 2019: https://www.cidrap.umn.edu/newsperspective/2019/08/drc-ebola-impact-getting-worsechildren\#: :text=The\%20agency\%20noted\%20that\%201,impact\%20on\%20kids\%20has\%20increased.
} 
Children are unlikely to be the first recipients of COVID-19 vaccine, as they generally are in malaria immunisation programmes (Blair in Sisay et al., 2020: 7). Children aged five years and younger are the most vulnerable age group affected by malaria, although this age group has been relatively spared from COVID-19 mortality and severe morbidity so far (Anjorin et al., 2020). Multiple immunisation programmes running concurrently with COVID-19 vaccination will have long-term benefits. National immunisation programmes globally are at risk of suspension due to the severe health system constraints and physical distancing measures in place to mitigate the ongoing COVID-19 pandemic. Benefit-risk analysis has concluded that routine childhood immunisation should be sustained in Africa as much as possible during the COVID-19 pandemic (Abbas et al., 2020).

\section{Global and national co-operation for increased uptake}

International co-operation and assistance between developed and developing countries is crucial in ensuring that all relevant health technologies, intellectual property data and know-how on COVID-19 vaccines and treatment are widely shared as a global public good (OHCHR, 2020a).

Global solidarity is needed to tackle COVID-19 successfully:

Each country that was a potential recipient of vaccine was asked to draw up a National Deployment and Vaccination Plan (NDVP) for A(H1N1)pdm09 vaccination in line with the Strategic Advisory Group of Experts (SAGE) recommendations, which included vaccination for healthcare workers, pregnant women, and persons with chronic diseases, as well as for children and other groups of individuals who may have been prioritised by the country. ${ }^{55}$

Update policies for universal health coverage (UHC)

UHC is needed in order to leave no-one behind in COVID-19 treatment:

WHO antiretroviral therapy (ART) guidelines have evolved from "treating the sickest" to "treating all" (Assefa et al., 2020). This has achieved successes in increasing ART coverage in all populations and locations. However, global data has shown inequity in ART coverage: women (68\%) versus men (55\%), and adults (62\%) versus children (54\%) (Assefa et al., 2020). This inequity has widened over time, and with expanded ART eligibility criteria. Although, data from at least one high-burden country (Ethiopia) shows that inequity among regions has narrowed over time. This is due to the improvements in the primary health care systems and implementation of the more inclusive public health approach.

\section{Overcome cultural barriers to healthcare}

Consider racism, including community and institutionalised racism

To achieve equitable coverage of COVID-19 vaccinations, former or existing prejudices must be considered:

\footnotetext{
55 Strategic advisory group of experts on immunization-report of the extraordinary meeting on the influenza A(H1N1) 2009 pandemic. 7 July 2009. Wkly Epidemiol Rec, 2009, 84, 301-304.
} 
It is often the most marginal and vulnerable groups who are systematically ignored and not reached by biomedical interventions (Wilkinson et al., 2017). Reasons for resistance are multiple, ranging from contradictory messaging, unsafe and degrading conditions in hospitals, and histories of violence, extraction (bribery) and corruption - which fed fears that Ebola (or the chlorine disinfectant spray) was a means of ethnic cleansing (Wilkinson et al., 2017).

\section{Improve socio-cultural perceptions of vaccination}

Train health professionals to explain COVID-19 risks to vulnerable groups:

Communication around the vaccine is crucial as negative community perceptions and understandings of why some people are vaccinated and others not, augments social risks associated with "distrust, suspicion and stigmatization" (Alcayna-Stevens, 2018: 29). Health care workers also need to be mindful not to engage in discriminatory practices and improve immunisation recommendations (Ozawa et al., 2019):

Faced with many issues related to language and culture, beginning with understanding and communicating perceptions of Ebola risk, vaccination and treatment helped with the marginalised and vulnerable BaTwa population of Équateur, DR Congo (Haug 2018). BaTwa are also referred to as Historically Marginalized Peoples (HMPs) as they are culturally different from the rest of the country, although this label has been criticised. ${ }^{56}$ The BaTwa group lives interdependently with agricultural Bantu ${ }^{57}$-speaking populations in Burundi, eastern DR Congo, Rwanda, Tanzania, and Uganda. The Batwa minority indigenous community were labelled as transmitters of the disease, and experienced discrimination in their access to health services from the staff (Bedford 2018a, Duda et al. 2018). In order to inform the BaTwa about protecting their health, UN surveillance and risk communication teams accompanied Bantu acquaintances which the Batwa villagers had previously met and trusted.

Between 1999 and 2008, the CORE Group Polio Project (CGPP) trained 250,000 "mobilizers" (including community health workers, community leaders, and lay supporters in the community) to provide essential, culturally relevant information about polio to mothers and caretakers as part of the GPEI to access the "chronically unreached, marginalized and most vulnerable populations in the world" (Losey et al., 2019). The percentage of children younger than five years of age who were missed in any supplemental immunisation activity in Nigeria decreased from $4.5 \%$ to $1.5 \%$. In India, the percentage of houses missed decreased from $5.9 \%$ to $4.4 \%$.

\section{Understand religious concerns with vaccines}

The COVID-19 vaccine must be available for use by all religious groups:

A halal (acceptable to Muslims) vaccine was the main factor that determined Malay participants' decision to accept vaccination uptake of the $2009 \mathrm{H} 1 \mathrm{~N} 1$ influenza vaccine in a multi-ethnic Asian population of Malaysia (Wong \& Sam, 2010). In 2018, the Indonesian Ulema Council, the Muslim

\footnotetext{
56 Nsanzimana G (2019). “Are We Batwa or 'Historically Marginalized People'?”: 10 June 2019: https://www.chronicles.rw/2019/06/10/are-we-batwa-or-historically-marginalized-people/

57 'Bantu' refers to a linguistic family that includes Twa.
} 
clerical body that issues certifications that a product is halal, or permissible under Islamic law, decreed that the measles and rubella vaccines were "haram," or unlawful, because of the pork-derived gelatin used as a stabiliser. Measles cases subsequently spiked, giving Indonesia the third-highest rate of measles in the world. A decree was later issued by the Muslim clerical body saying it was permissible to receive the vaccine, however, cultural taboos still led to continued low vaccination rates. ${ }^{58}$

\section{Overcome socio-political barriers to healthcare}

Political support for COVID-19 vaccination roll-out is important:

The findings of declining vaccine confidence in Afghanistan, Azerbaijan, Pakistan, and Nigeria mirrored trends in political instability and religious extremism in these settings (de Figueiredo et al., 2020: 906). Therefore, successful immunisation campaigns must secure the support of the existing political leaders. In Somalia, the terrorist group al-Shabaab had forbidden polio workers from operating in areas under their control, viewing vaccination campaigns as part of a foreign campaign to impose a centralised government. One million children were unvaccinated between 2010 and 2013, when a polio outbreak occurred. Since then, immunisation campaigns have improved their access to rebel-controlled areas by employing locally recruited staff to work within their own clans, and negotiate access with local-level militant leaders (Kennedy \& Michailidou, 2016).

\section{Overcome socio-economic and socio-political barriers to health}

The impacts of COVID-19 to date have been significant on health, the economy and society (e.g. occupation, education, wealth, and housing):

Achieving global equitable vaccination will boost economies, improve global health security, and help achieve the Sustainable Development Goals (SDGs): not just those related to health, but also poverty, inequalities, education, and more..$^{59}$ However, vaccination coverage is not uniform across various socio-economic groups (Ndwandwe et al., 2018).

Across many parts of the world, governments, humanitarian responders and communities confront multiple challenges where the response to public health emergencies must compete for human, financial and health service resources (Carter et al., 2020). However, many people in vulnerable groups - including hard-to-reach or hard-to-vaccinate populations - have little confidence that their government will protect them from COVID-19 (Burgess et al., 2020).

Governments must take all measures necessary to ensure that COVID-19 medical products are affordable, equitably accessible by vulnerable and marginalised groups, and distributed according to public health need. This will require governments to set clear guidelines for the fair and equitable distribution of treatments for their own populations (Bollyky et al., 2020):

\footnotetext{
58 Concern among Muslims over halal status of COVID-19 vaccine. 20 December 2020: https://www.independent.co.uk/news/concern-among-muslims-over-halal-status-of-covid19-vaccine-muslimcovid-law-vaccine-novartis-b1776700.html

${ }^{59}$ Moving towards equitable access to vaccination - The Lancet Infectious Diseases: https://www.thelancet.com/journals/laninf/article/PIIS1473-3099(19)30487-6/fulltext
} 
Share vaccine supplies with LMICs and monitor for equality

The COVID-19 virus has spread fast, and caused huge socio-economic changes across the globe. Therefore, international collaboration is needed for equitable distribution of vaccines:

During the $2009 \mathrm{H} 1 \mathrm{~N} 1$ pandemic, wealthy nations bought virtually all vaccine supplies. Even after the WHO appealed for donations, supplies for LMICs were limited (Bollyky et al., 2020). To provide vaccination against infection due to the 2009 pandemic influenza A virus subtype H1N1 $A(H 1 N 1) p d m 09$ to resource-constrained countries with otherwise very little access to the $\mathrm{A}(\mathrm{H} 1 \mathrm{~N} 1)$ pdm09 vaccine, the WHO co-ordinated distribution of donated vaccine to selected countries worldwide. Bangladesh was due to receive the largest share: 12.6 million doses. From February through to November 2010, 32.2 million doses were delivered to 34 countries in Africa. Data from these surveillance systems from 2010-2012 showed that influenza A(H1N1)pdm09 circulated in West Africa later than in other regions of the continent. Several countries throughout western Africa captured young children, but lacked data on adults and older people. ${ }^{60} \mathrm{~A}$ number of African countries have provided regular updates to WHO on the spread of influenza $\mathrm{A}(\mathrm{H} 1 \mathrm{~N} 1)$ pdm09, however, the impact of the pandemic on the African continent is not apparent. ${ }^{61}$ Therefore, this indicates a need to strengthen surveillance systems to assess the effect of the pandemic and monitor the impact of influenza in general.

60 Nzussouo, N.T., Duque, J., Adedeji, A., et al. (2017). Epidemiology of influenza in West Africa after the 2009 influenza $A(H 1 N 1)$ pandemic, 2010-2012. BMC Infect Dis, 17, 745: https://doi.org/10.1186/s12879-017-2839-1

61 WHO - Africa Flu Alliance: https://www.who.int/influenza/preparedness/africa_flu/en/ 


\section{References}

Abbas, K., Procter, S.R., van Zandvoort, K., et al. (2020). Routine childhood immunisation during the COVID-19 pandemic in Africa: a benefit-risk analysis of health benefits versus excess risk of SARS-CoV-2 infection. The Lancet Global Health, 8, e1264-72. https://doi.org/10.1016/S2214$109 \times(20) 30308-9$

Abuelgasim, E., Saw, L. J., Shirke, M., Zeinah, M., \& Harky, A. (2020). COVID-19: Unique public health issues facing Black, Asian and minority ethnic communities. Current Problems in Cardiology, 45(8), 100621. https://doi.org/10.1016/j.cpcardiol.2020.100621

Al Saba, R. (2020). Inequality and the impact of Covid-19: How discrimination is shaping the experiences of minorities and indigenous peoples during the pandemic. Minority Rights Group International. https://minorityrights.org/publications/covid-briefing/

Alcayna-Stevens, L. (2018). Planning for Post-Ebola: Lessons learned from DR Congo's 9th epidemic. SSHAP. Geneva: UNICEF. https://www.socialscienceinaction.org/resources/planningpost-ebola-lessons-learned-dr-congos-9th-epidemic/

Anjorin, A.A., Abioye, A.I., Asowata, O.E., et al. (2020). Comorbidities and the COVID-19 pandemic dynamics in Africa. TMIH, 26(1), 2-13. https://doi.org/10.1111/tmi.13504

Armitage R. \& Nellums L.B. (2020). The COVID-19 response must be disability inclusive. The Lancet Public Health, 5(5), e257. DOI: 10.1016/S2468-2667(20)30076-1

ASEAN Briefing (2021). COVID-19 Vaccine Roll Outs in ASEAN \& Asia - Live Updates by Country. https://www.aseanbriefing.com/news/covid-19-vaccine-roll-outs-in-asean-asia-liveupdates-by-country/

Assefa, Y., Hill, P.S., Van Damme, W., et al. (2020). Leaving no one behind: lessons from implementation of policies for universal HIV treatment to universal health coverage. Global Health, 16, 17. https://doi.org/10.1186/s12992-020-00549-4

Bedford, J. (2018a). Key considerations: changing behaviours \& care-seeking practices in the Grand Nord, North Kivu, DRC. Social Science in Humanitarian Action.

https://www.anthrologica.com/application/files/4415/6750/3098/SSHAP_Changing_behaviours_a nd_care_seeking_practices-min.pdf

Bedford, J. (2018b). Key considerations: health-seeking behaviours in Équateur Province, DRC. Social Science in Humanitarian Action.

https://opendocs.ids.ac.uk/opendocs/bitstream/handle/20.500.12413/13826/SSHAP_Key_consid erations_health_beliefs_and_health_seeking_behaviours.pdf? sequence $=1$ \&isAllowed $=y$

Bisca, P.M., \& Bance, P. (2019). Can public works help fight Ebola in the Democratic Republic of Congo? 31 July 2019. https://www.brookings.edu/blog/future-development/2019/07/31/can-publicworks-help-fight-ebola-in-the-democratic-republic-of-congo/

Bollyky, T.J., Gostin, L.O., \& Hamburg, M.A. (2020). The Equitable Distribution of COVID-19 Therapeutics and Vaccines. JAMA, 323(24), 2462-2463. DOI: 10.1001/jama.2020.6641 
Brownwright, T.K., Dodson, Z.M., \& van Panhuis, W.G. (2017). Spatial clustering of measles vaccination coverage among children in sub-Saharan Africa. BMC Public Health, 17, 957. https://doi.org/10.1186/s12889-017-4961-9

Burgess, R.A., Osborne, R.H., Yongabi, K.A., et al. (2020). The COVID-19 vaccines rush: participatory community engagement matters more than ever. Lancet, 397(10268), 8-10. DOI: https://doi.org/10.1016/S0140-6736(20)32642-8

Burki, T. (2020). The indirect impact of Covid-19 on women. The Lancet, 20(8), 904-905. DOI: 10.1016/S1473-3099(20)30568-5

Carter, S.E., Gobat, N., Pfaffmann Zambruni, J., et.al. (2020). What questions we should be asking about COVID-19 in humanitarian settings: perspectives from the Social Sciences Analysis Cell in the Democratic Republic of the Congo. BMJ Global Health, 5.9. http://dx.doi.org/10.1136/bmjgh-2020-003607

Child, D. (2019). DRC: Roll-out of second Ebola vaccine confirmed amid criticism. 23 September 2019. https://www.aljazeera.com/news/2019/9/23/drc-roll-out-of-second-ebola-vaccineconfirmed-amid-criticism

Chiriboga D., Garay J., Buss P., Madrigal , R.S., \& Rispel, L.C. (2020). Health inequity during the COVID-19 pandemic: a cry for ethical global leadership. The Lancet, 395, 1690-1691. DOI: https://doi.org/10.1016/S0140-6736(20)31145-4

Chowell, G., Tariq, A., \& Kiskowski, M. (2019). Vaccination strategies to control Ebola epidemics in the context of variable household inaccessibility levels. PLOS Negl Trop Dis, 13(11), e0007814. https://doi.org/10.1371/journal.pntd.0007814

Cohen, J. (2018). As massive Zika vaccine trial struggles, researchers revive plan to intentionally infect humans. 12 September 2018. https://www.sciencemag.org/news/2018/09/massive-zikavaccine-trial-struggles-researchers-revive-plan-intentionally-infect

Cotterill, J. (2020). South Africa's mass screening helps stem the coronavirus tide. 5 May 2020. https://www.ft.com/content/98d0d7c6-9bfb-4a64-bcab-19e0854a3b4d

Crank, J. (2020). For LGBTQ Patients, the Coronavirus Brings New Challenges. 25 June 2020. https://www.hopkinsmedicine.org/health/conditions-and-diseases/coronavirus/for-lgbtq-patientsthe-coronavirus-brings-new-challenges

Dada, S., McKay, G., Mateus, A., et al. (2019). Lessons learned from engaging communities for Ebola vaccine trials in Sierra Leone: reciprocity, relatability, relationships and respect (the four R's). BMC Public Health, 19, 1665. https://doi.org/10.1186/s12889-019-7978-4

Daniel, L. (2021). How and where to get tested for Covid-19 in South Africa. Business Insider SA. 11 December 2020. https://www.businessinsider.co.za/how-and-where-to-get-tested-for-covid19-in-sa-2020-12

DeBruin, D., Liaschenko, J., \& Marshall, M.F. (2012). Social justice in pandemic preparedness. American Journal of Public Health, 102(4), 586-591.

https://doi.org/10.2105/AJPH.2011.300483 
de Figueiredo, A., Simas, C., Karafillakis, E., Paterson, P., \& Larson, H.J. (2020). Mapping global trends in vaccine confidence and investigating barriers to vaccine uptake: a large-scale retrospective temporal modelling study. Lancet, 396(10255), 898-908. DOI: https://doi.org/10.1016/S0140-6736(20)31558-0

Dodds, C., \& Fakoya, I. (2020). Covid-19: ensuring equality of access to testing for ethnic minorities. Editorial. BMJ, 369. DOI: https://doi.org/10.1136/bmj.m2122

Duda, R., Alcayna-Stevens, L., \& Bedford, J. (2018). Key Considerations: Engaging Twa Communities in Équateur Province. Brighton: UNICEF, IDS and Anthrologica. https://doi.org/10.7490/f1000research.1115740.1

Ghai, R. (2021). Female health workers played a critical role in making Africa wild polio-free. 29 January 2021. https://www.downtoearth.org.in/interviews/africa/-female-health-workers-played-acritical-role-in-making-africa-wild-polio-free--75259

Harman, S., Herten-Crabb, A., Morgan, R., Smith, J., \& Wenham, C. (2020). COVID-19 vaccines and women's security. Comment. The Lancet, 1-2. DOI: https://doi.org/10.1016/S01406736(20)32727-6

Haug, C.J. (2018). Keeping Your Cool - Doing Ebola Research during an Emergency. N Engl J Med, 78, 2353-2355. DOI: 10.1056/NEJMp1806978

Holland, H. (2020). On Congo's muddy trails, lessons for a global COVID vaccine rollout. 22 December 2020. https://uk.reuters.com/article/health-coronavirus-congo-vaccine/on-congosmuddy-trails-lessons-for-a-global-covid-vaccine-rollout-idUKKBN28WOLN

IDA (2020). Voices of some under-represented groups from Uganda. 12 June 2020. International Disability Alliance. https://www.internationaldisabilityalliance.org/blog/voices-some-underrepresented-groups-uganda

IRC (2021). Billions will not receive a COVID-19 vaccine in 2021. Press Release. 12 January 2021. International Rescue Committee. https://www.rescue-uk.org/press-release/billions-will-notreceive-covid-19-vaccine-2021

Jain, V., Baker, P., Mehndiratta, A., \& Chalkidou, K. (2020). Using COVID-19 Test, Trace, and Isolate Systems Effectively in Middle-Income Countries. 21 August 2020.

https://www.cgdev.org/publication/using-covid-19-test-trace-and-isolate-systems-effectivelymiddle-income-countries

Johns, M., Lockwood, R., Longlands, S., Qureshi, A., \& Round, A. (2020). State of the North 2020/21: power up, level up, rise up. Institute for Public Policy Research (IPPR) North, 2020. http://www.ippr.org/research/publications/state-of-the-north-2020-21

Kamugisha, C., Cairns, K.L., \& Akim, C. (2003). An Outbreak of Measles in Tanzanian Refugee Camps. The Journal of Infectious Diseases, 187(1), S58-S62. http://www.jstor.org/stable/30085439

Kamya, M. (2020). EVALUATION OF THE DRIVERS OF URBAN IMMUNISATION IN UGANDA: A CASE STUDY OF KAMPALA CITY. MAY 2020.

https://www.gavi.org/sites/default/files/evaluations/Evaluation-of-drivers-of-urban-immunisationUganda-Kampala-case-study-Phase1.pdf 
Kennedy, J., \& Michailidou, D. (2016). The barriers to polio eradication are no longer medical, they're geopolitical. 16 March 2016. World Economic Forum.

https://www.weforum.org/agenda/2016/03/the-barriers-to-polio-eradication-are-no-longermedical-theyre-geopolitical

Kew, J. (2021). South Africa Allows Use of Parasite Drug in Covid Patients. 27 January 2021updated 28 January. https://www.bloomberg.com/news/articles/2021-01-27/south-africa-allowsuse-of-parasite-drug-to-treat-covid-patients

Khunti, K., Singh, A.K., Pareek, M., \& Hanif, W. (2020). Is ethnicity linked to incidence or outcomes of covid-19? BMJ, 369. DOI: https://doi.org/10.1136/bmj.m1548

Klass, P., \& Ratner, A.J., (2021). Vaccinating Children against Covid-19 - The Lessons of Measles. Perspective. NEJM, 1-2. DOI: 10.1056/NEJMp2034765

Kluge, H.H.P., Jakab, Z., Bartovic, J, D'Anna, V., \& Severoni, S. (2020). Refugee and migrant health in the COVID-19 response. The Lancet, 395(10232), 1237-1239. DOI:

https://doi.org/10.1016/S0140-6736(20)30791-1

Kouadio, I.K., Koffi, A.K., Attoh-Toure, H., Kamigaki, T., \& Oshitani, H. (2009). Outbreak of measles and rubella in refugee transit camps. Epidemiology and Infection, 137, 1593-1601. DOI:10.1017/S0950268809002520

Kuper H., Banks L.M., Bright T., Davey C. \& Shakespeare T. (2020). Disability-inclusive COVID19 response: What it is, why it is important and what we can learn from the United Kingdom's response. Wellcome Open Research, 5(79), 2-8. DOI: 10.12688/wellcomeopenres.15833.1

Lenhardt, A. (2020). Lessons learned from Ebola Outbreak 9 in Equateur, Democratic Republic of the Congo. K4D Helpdesk Report 845. Brighton, UK: Institute of Development Studies. https://opendocs.ids.ac.uk/opendocs/bitstream/handle/20.500.12413/15451/845_Lessons_learne d_from_Ebola_outbreak9_in_Equateur_Province_DRC.pdf?sequence $=1$ \&isAllowed $=y$

Losey, L., Ogden, E., Bisrat, F., et al. (2019). The CORE Group Polio Project: An Overview of Its History and Its Contributions to the Global Polio Eradication Initiative. The American Journal Of Tropical Medicine and Hygiene, 101(4), 4-14. https://doi.org/10.4269/ajtmh.18-0916

Maxmen, A. (2019). Aid group says Ebola vaccine is not reaching enough people. 23 September 2019. Nature. https://www.nature.com/articles/d41586-019-02879-9

Mbazzi, F.B., Nalugya, R., Kawesa, E., et al. (2021). The impact of COVID-19 measures on children with disabilities and their families in Uganda. Disability \&

Society. DOI: 10.1080/09687599.2020.1867075

McKinney, E. L., McKinney, V., \& Swartz, L. (2020). COVID-19, disability and the context of healthcare triage in South Africa: Notes in a time of pandemic. African Journal of Disability, 9 , 766. https://doi.org/10.4102/ajod.v9i0.766

Merriam, S., \& Behrendt, H. (2020). Increasing vaccine uptake in low- and middle-income countries. The Behavioural Insights Team. https://www.bi.team/wp- 
content/uploads/2020/04/Opportunities-for-behavioural-insights-research-on-vaccines-uptake-inlow-and-middle-income-countries.pdf

Mihigo,R., Torrealba, C.V., Coninx, K., et al. (2012). 2009 Pandemic Influenza A Virus Subtype H1N1 Vaccination in Africa - Successes and Challenges. The Journal of Infectious Diseases, 206(1), S22-S28. https://doi.org/10.1093/infdis/jis535

Mirzoez, T.," \& Tull, K.I, ${ }^{*}$ Winn, N., Mir, G., et al. (2021). Systematic review of the role of social inclusion within sustainable urban developments. In preparation. ${ }^{*}$ Joint first authorship

Mixed Migration Centre (2020a). Understanding the Impact of COVID-19 on Refugees and Migrants in Kenya and Somaliland. Technical report. May 2020. http://www.mixedmigration.or/pconten/pload/02//04_covid_snapshot_EAY.pdf

Mixed Migration Centre (2020b). Refugees' and Migrants' Access to Health Services in Tunisia: A Focus on Discrimination and COVID-19. Technical report. April 2020. http://www.mixedmigration.or/p-conten/pload/02//98_covid_snapshot_NA.pdf

Mogoatlhe, L. (2020). What Lessons Can We Learn From Polio in Tackling COVID-19? 18 August 2020. https://www.globalcitizen.org/en/content/polio-eradication-lessons-for-covid-19/

Mukumbang, F.C. (2020). Are asylum seekers, refugees and foreign migrants considered in the COVID-19 vaccine discourse? BMJ Global Health, 5, e004085. http://dx.doi.org/10.1136/bmjgh2020-004085

Mukumbang, F.C., Ambe, A.N., \& Adebiyi, B.O. (2020). Unspoken inequality: how COVID-19 has exacerbated existing vulnerabilities of asylum-seekers, refugees, and undocumented migrants in South Africa. Int J Equity Health, 19, 1-7. DOI:10.1186/s12939-020-01259-4

Mwai, P. (2021). Coronavirus: Why South Africa has yet to roll out vaccines. 20 January 2021. https://www.bbc.co.uk/news/world-africa-55675806

Ndwandwe, D., Uthman, O.A., Adamu, A.A., et al. (2018). Decomposing the gap in missed opportunities for vaccination between poor and non-poor in sub-Saharan Africa: a multicountry analyses. Hum Vaccin Immunother, 14(10), 2358-2364.

https://doi.org/10.1080/21645515.2018.1467685

OHCHR (2020a). Statement by UN Human Rights Experts Universal access to vaccines is essential for prevention and containment of COVID-19 around the world. 9 November 2020. Office of the United Nations High Commissioner for Human Rights.

https://www.ohchr.org/EN/NewsEvents/Pages/DisplayNews.aspx?NewsID=26484\&LangID=E\#_ft n9

OHCHR (2020b). Special Rapporteur on extreme poverty and human rights: The parlous state of poverty eradication. Report: A/HRC/44/40 (advanced unedited version).

https://www.ohchr.org/EN/lssues/Poverty/Pages/AnnualReports.aspx

OHCHR (2020c). Report on the impact of the COVID-19 pandemic on the human rights of LGBT persons. A/75/258. Office of the United Nations High Commissioner for Human Rights. https://www.ohchr.org/EN/lssues/SexualOrientationGender/Pages/COVID19Report.aspx 
OHCHR (2020d). An LGBT-inclusive response to COVID-19. Office of the United Nations High Commissioner for Human Rights.

https://www.ohchr.org/EN/Issues/SexualOrientationGender/Pages/COVID19LGBTInclusiveResp onse.aspx

OHCHR (2020e) Protection against violence and discrimination based on sexual orientation and gender identity. 28 July 2020. A/75/258 Note by the Secretary-General.

https://undocs.org/A/75/258

Ozawa, S. (2019). 5 Questions About Defining Hard-to-Reach Populations for Vaccination. https://www.consultant360.com/exclusive/infectious-diseases/vaccines/5-questions-aboutdefining-hard-reach-populations

Ozawa, S., Yemeke, T.T., Evans, D.R., et al. (2019). Defining hard-to-reach populations for vaccination. Vaccine, 37(37), 5525-5534. DOI: 10.1016/j.vaccine.2019.06.081

Pesa, I. (2020). Discriminating epidemics: Ebola and COVID-19 in the Democratic Republic of Congo. 8 April 2020. https://www.torch.ox.ac.uk/article/discriminating-epidemics-ebola-andcovid-19-in-the-democratic-republic-of-congo

Public Health England (2020). People with learning disabilities had higher death rate from COVID-19. 12 November 2020. https://www.gov.uk/government/news/people-with-learningdisabilities-had-higher-death-rate-from-covid-19

Rafaeli, T., \& Hutchinson, G. (2020). The Secondary Impacts of COVID-19 on Women and Girls in Sub-Saharan Africa. K4D Helpdesk Report 830. Brighton, UK: Institute of Development Studies.

https://opendocs.ids.ac.uk/opendocs/bitstream/handle/20.500.12413/15408/830_COVID19_girls _and_women_SSA.pdf?sequence=1\&isAllowed=y

Rahi, M., \& Sharma, A. (2020). Mass vaccination against COVID-19 may require replays of the polio vaccination drives. E Clinical Medicine, 25, 100501. DOI:

https://doi.org/10.1016/j.eclinm.2020.100501

Rajan, D., Koch, K., Rohrer, K., et al. (2020). Governance of the Covid-19 response: a call for more inclusive and transparent decision-making. BMJ Glob Health, 5(5), e002655. DOI:

10.1136/bmjgh-2020-002655 pmid:32371570

Roelen, K., Ackley, C., Boyce, P., et al. (2020). COVID-19 in LMICs: The Need to Place Stigma Front and Centre to Its Response. Eur J Dev Res, 32, 1592-1612.

https://doi.org/10.1057/s41287-020-00316-6

Rohan, H., \& McKay, G. (2020). The Ebola outbreak in the Democratic Republic of the Congo: why there is no 'silver bullet'. Nat Immunol, 21, 591-594. https://doi.org/10.1038/s41590-0200675-8

Rohwerder, B. (2014). Impact and implications of the Ebola crisis. GSDRC Helpdesk Research Report 1177. Birmingham, UK: GSDRC, University of Birmingham.

http://www.gsdrc.org/docs/open/hdq1177.pdf 
Sadlier, M. (2020). I can't stop shouting about vaccines. World Vision International. https://www.wvi.org/stories/view/i-cant-stop-shouting-about-vaccines

Sarma, H., Budden, A., Luies, S.K. et al. (2019). Implementation of the World's largest measlesrubella mass vaccination campaign in Bangladesh: a process evaluation. BMC Public Health, 19, 925. https://doi.org/10.1186/s12889-019-7176-4

Sanyaolu, A., Okorie, C., Marinkovic, A., et al. (2020). Comorbidity and its Impact on Patients with COVID-19. SN Comprehensive Clinical Medicine, 1-8. https://doi.org/10.1007/s42399-02000363-4

Shelley-Egan, C., \& Dratwa, J. (2019). Marginalisation, Ebola and Health for All: From Outbreak to Lessons Learned. Int J Environ Res Public Health, 16, 3023.

https://doi.org/10.3390/ijerph16173023

Simas, C., Penn-Kekana, L., Kuper, H., et al. (2020). Hope and trust in times of Zika: the views of caregivers and healthcare workers at the forefront of the epidemic in Brazil. Health Policy and Planning, 35(8), 953-961. DOI: https://doi.org/10.1093/heapol/czaa042

Singh, B., Suresh, K., Kumar, S., \& Singh, P. (1997). Pulse polio immunization in Delhi--1995-96: a survey. Indian J Pediatr, 64, 57-64. DOI: 10.1007/BF02795777

Sisay, O.B., Smith, E., Crone, D., Andersen, H., \& Mamo, L.T. with forward by Blair, T. (2020). A Covid-19 Vaccination Plan for Africa. https://institute.global/sites/default/files/articles/A-Covid-19Vaccination-Plan-for-Africa.pdf

Stanturf, J.A., Goodrick, S.L., Warren, M.L. Jr, Charnley, S., \& Stegall, C.M. (2015). Social Vulnerability and Ebola Virus Disease in Rural Liberia. PLoS One, 10(9): e0137208. DOI: 10.1371/journal.pone.0137208

Sze , S., Pan, D., Nevill, C.R., et al. (2020). Ethnicity and clinical outcomes in COVID-19: A systematic review and meta-analysis. E Clinical Medicine, 9, 100630. DOI:

https://doi.org/10.1016/j.eclinm.2020.100630

Tull, K. (2019). Vaccine hesitancy: guidance and interventions. K4D Helpdesk Report 672. Brighton, UK: Institute of Development Studies.

https://opendocs.ids.ac.uk/opendocs/bitstream/handle/20.500.12413/14747/672_Vaccine_Hesita ncy.pdf?sequence $=1$ \&isAllowed $=y$

UN (2018). 'Indigenous peoples and ethnic minorities: marginalization is the norm', in Promoting Inclusion through Social Protection: Report on the World Social Situation. United Nations. https://www.un.org/development/desa/dspd/world-social-report/2018-2.html

UN Women (2020). Policy Brief: The Impact of COVID-19 on Women. 9 APRIL 2020. United Nations. https://www.unwomen.org//media/headquarters/attachments/sections/library/publications/2020/policy-brief-the-impact-ofcovid-19-on-women-en.pdf?la=en\&vs=1406 
Uzicanin, A., Eggers, R., Webb, E., et al. (2002). Impact of the 1996-1997 supplementary measles vaccination campaigns in South Africa. International Journal of Epidemiology, 31(5), 968-976. https://doi.org/10.1093/ije/31.5.968

Weiss, W.M., Winch, P.J., \& Burnham, G. (2009). Factors Associated with Missed Vaccination during Mass Immunization Campaigns. J HEALTH POPUL NUTR, 27(3), 358-367.

http://www.bioline.org.br/pdf?hn09034

Wells, C., Pandeya, A., Parpiaa, A., Fitzpatricka, M. Meyersc, L., Singerd, B. \& Galvania, A. (2019). Ebola vaccination in the Democratic Republic of the Congo. Proceedings of the National Academy of Sciences of the United States of America, 116(20), 10178-10183.

https://www.pnas.org/content/pnas/116/20/10178.full.pdf

WHO (2020a). WHO SAGE values framework for the allocation and prioritization of COVID-19 vaccination. 14 September 2020. World Health Organization.

https://apps.who.int/iris/bitstream/handle/10665/334299/WHO-2019-nCoV-SAGE_FrameworkAllocation_and_prioritization-2020.1-eng.pdf

WHO (2020b). Ebola virus disease - Democratic Republic of the Congo. 18 November 2020. World Health Organization. https://www.who.int/csr/don/18-november-2020-ebola-drc/en/

Wilkinson, A., Parker, M., Martineau, F., \& Leach, M. (2017). Engaging 'communities': anthropological insights from the West African Ebola epidemic. Phil Trans $R$ Soc B, 372, 20160305. https://doi.org/10.1098/rstb.2016.0305

Willen, S.S., Knipper, M., Abadía-Barrero, C.E., \& Davidovitch, N. (2017). Syndemic vulnerability and the right to health. Lancet, 389, 964-977. DOI: https://doi.org/10.1016/S0140-

6736(17)30261-1

Wong, L.P., \& Sam, I.C. (2010). Factors influencing the uptake of 2009 H1N1 influenza vaccine in a multiethnic Asian population. Vaccine, 28(28), 4499-4505. DOI:

10.1016/j.vaccine.2010.04.043

\section{Acknowledgements}

We thank the following experts who voluntarily provided suggestions for relevant literature or other advice to the author to support the preparation of this report. The content of the report does not necessarily reflect the opinions of any of the experts consulted.

- Clarissa Simas - The Vaccine Confidence Project, LSHTM

\section{Key websites}

- The EBODAC (Ebola Vaccine Deployment, Acceptance and Compliance) Project: https://www.ebovac.org/ebodac/

- South African COVID-19 Vulnerability Index Dashboard: https://app.powerbi.com/view?r=eyJrljoiZTNINmNjMWUtZTQwMC00YjA5LWI0ODUtZGV IYmVIYjJkZjcxliwidCI6ImNhMzhhOWU1LThjZTItNDFIOC1hNDFILTYON2M3YjUwZGIOY SIsImMiOjl9 


\title{
Suggested citation
}

Tull, K. (2021). Social inclusion and immunisation. K4D Helpdesk Report 955. Brighton, UK: Institute of Development Studies. DOI: 10.19088/K4D.2021.025

\begin{abstract}
About this report
This report is based on twelve days of desk-based research. The K4D research helpdesk provides rapid syntheses of a selection of recent relevant literature and international expert thinking in response to specific questions relating to international development. For any enquiries, contact helpdesk@k4d.info.
\end{abstract}

K4D services are provided by a consortium of leading organisations working in international development, led by the Institute of Development Studies (IDS), with Education Development Trust, Itad, University of Leeds Nuffield Centre for International Health and Development, Liverpool School of Tropical Medicine (LSTM), University of Birmingham International Development Department (IDD) and the University of Manchester Humanitarian and Conflict Response Institute (HCRI).

This report was prepared for the UK Government's Foreign, Commonwealth and Development Office (FCDO) and its partners in support of pro-poor programmes. It is licensed for non-commercial purposes only. Except where otherwise stated, it is licensed for non-commercial purposes under the terms of the Open Government Licence v3.0. K4D cannot be held responsible for errors, omissions or any consequences arising from the use of information contained in this report. Any views and opinions expressed do not necessarily reflect those of FCDO, K4D or any other contributing organisation.

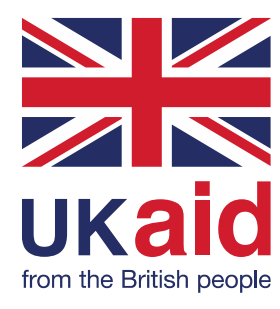

(C) Crown copyright 2021. 